\title{
HUBUNGAN LINGKAR KEPALA DAN PERKEMBANGAN BAYI DI POLI BAYI \& TUMBUH KEMBANG RSUP PROF. DR. R. D. KANDOU
}

\author{
${ }^{1}$ Dennis Thezar \\ ${ }^{2}$ Nurhayati Masloman \\ ${ }^{2}$ Jose M. Mandei \\ ${ }^{1}$ Mahasiswa Skripsi Fakultas Kedokteran Universitas Sam Ratulangi Manado \\ ${ }^{2}$ Bagian Ilmu Kesehatan Anak Fakultas Kedokteran Universitas Sam Ratulangi Manado \\ - RSUP Prof. Dr. R. D. Kandou Manado \\ Email: dthez94@gmail.com
}

Background: Around $10 \%$ of the world's children have delayed development. Head circumference is used as one of the indicator to identify neurological impairment and to detect the cause of developmental delay. Yet, microcephaly or macrocephaly are not always indicated a delayed development on children. Objectives: To find out the overview of head circumference and child's development in the Child Development Center of Kandou Public Hospital and to determine the relation between both of it. Methods: This study is an analytical cross-sectional study. Data were collected with head measurement and KPSP (Kuesioner praskrining perkembangan) to assess development in the Growth and Development Clinic of Kandou Public Hospital from November 2015 to January 2016. The data were analyzed using Fisher's exact statistical test. Results: From 34 subjects who qualified the inclusion criteria: $50 \%$ of the subjects are male, most subjects were using the third month KPSP, there are $97.1 \%$ subjects with normal head circumference, $88.2 \%$ with normal development, and the study is not statistical significant with Fisher's exact test ( $\mathrm{p}=$ 0.882). Conclusions: There is no significant relation between head circumference and development. Most of the infants have normal head circumference and development.

Keywords: Head circumference, development, KPSP

Latar Belakang: Anak-anak dengan keterlambatan perkembangan secara umum meliputi $10 \%$ anak-anak di seluruh dunia. Ukuran lingkar kepala adalah salah satu indikator yang umum diperiksa untuk mengidentifikasi kelainan neurologis dan menyingkirkan penyebab keterlambatan perkembangan. Namun, mikrosefali atau makrosefali belum tentu menandakan penyimpangan perkembangan pada anak. Tujuan: Untuk mengetahui gambaran lingkar kepala dan perkembangan bayi di Poli Bayi \& Tumbuh Kembang RSUP Prof. Dr. R.D. Kandou serta hubungan antara keduanya. Metode: Penelitian ini merupakan penelitian analitik potong lintang. Data dikumpulkan dengan cara pengukuran lingkar kepala dan KPSP (Kuesioner praskrining perkembangan) untuk penilaian perkembangan di Poli Bayi \& Tumbuh Kembang RSUP Prof. Dr. R.D. Kandou dari November 2015 hingga Januari 2016. Analisa data menggunakan uji statistik Fisher's exact. Hasil: Dari 34 subjek yang memenuhi kriteria inklusi: 50\% berjenis kelamin laki-laki, terbanyak menggunakan KPSP 3 bulan, 97,1\% dengan lingkar kepala normal, 88,2\% dengan perkembangan normal, dan penelitian ini tidak signifikan secara statistik dengan uji Fisher's exact $(\mathrm{p}=0,882)$. Kesimpulan: Tidak terdapat hubungan yang bermakna antara lingkar kepala dan perkembangan. Sebagian besar bayi memiliki ukuran lingkar kepala dan perkembangan yang normal.

Kata kunci: Lingkar kepala, perkembangan, KPSP 
Anak yang mengalami keterlambatan perkembangan dideskripsikan sebagai seorang anak yang memerlukan waktu lebih lama untuk mencapai milestones perkembangan dibandingkan dengan anak seusianya. Hal ini dapat bersifat sementara atau merupakan tanda dari kondisi intelektual lainnya atau autisme. ${ }^{1}$ Keterlambatan ini mencakup keterlambatan motorik halus, motorik kasar, bahasa/berbicara, personal sosial/ interaksi sosial, kognitif dan aktivitas sehari-hari. $^{1,2}$

Anak-anak dengan keterlambatan perkembangan secara umum meliputi $10 \%$ anak-anak di seluruh dunia. ${ }^{3-6} \mathrm{Di}$ Indonesia, penelitian tentang prevalensi keterlambatan masih minim dan terpusatkan di beberapa daerah saja sehingga belum dapat mewakili populasi secara umum. ${ }^{3,7,8}$ Berdasarkan penelitian sebelumnya, banyak anak yang mengalami keterlambatan perkembangan tidak terdeteksi di tingkat primer. ${ }^{9-11}$ Menurut Glascoe $^{12}$, keterlambatan perkembangan ini jarang terdeteksi karena banyak dokter lebih memilih menggunakan pendapat klinis dibandingkan alat skrining perkembangan.

Pemeriksaan klinis yang dilakukan berupa anamnesis, pemeriksaan fisik, dan penunjang yang mencakup semua aspek pertumbuhan dan perkembangan serta berdasarkan pada milestone perkembangan anak. ${ }^{13-15}$ Ukuran lingkar kepala adalah salah satu indikator yang umum diperiksa untuk mengidentifikasi kelainan neurologis dan menyingkirkan penyebab keterlambatan perkembangan. ${ }^{15-17}$ Namun, mikrosefali atau makrosefali belum tentu menandakan penyimpangan perkembangan pada anak. ${ }^{18,19}$

Untuk itu, skrining perkembangan dengan menggunakan cara/ alat yang telah distandarisasi seperti Denver developmental screening test II (DDST-II) lebih tepat untuk penilaian perkembangan anak. $^{20}$ Namun, DDST-II tidak praktis dilakukan di Indonesia dengan alasan waktu, tenaga ahli, dan biaya. ${ }^{21}$ Oleh karena itu, Depkes RI pada tahun 2005 mengeluarkan kuesioner praskrining perkembangan (KPSP) dengan tujuan identifikasi dini penyimpangan perkembangan dan dapat dilakukan di tingkat terbawah, kecamatan dan oleh tenaga kesehatan atau tenaga ahli yang terlatih. ${ }^{13,21-23}$

Deteksi dan intervensi dini perlu segera dilakukan pada anak yang dicurigai mengalami penyimpangan perkembangan, khususnya pada 3-5 tahun pertama anak untuk mencegah kelainan atau masalah perkembangan. ${ }^{7,13,24}$

Berdasarkan hal-hal di atas, maka peneliti ingin meneliti lingkar kepala dan praskrining perkembangan dengan KPSP pada bayi yang datang untuk imunisasi di Poli Bayi \& Tumbuh Kembang RSUP Prof. R. D. Kandou Manado dengan tujuan untuk menilai hubungan antara keduanya.

\section{METODE PENELITIAN}

Penelitian ini menggunakan desain penelitian analitik potong lintang. Penelitian ini dilaksanakan di Poli Bayi \& Tumbuh Kembang RSUP Prof. Dr. R. D. Kandou Manado pada bulan November 2015 hingga Januari 2016. Subjek penelitian adalah bayi sehat berusia 3-12 bulan lahir normal, status gizi baik, mendapat persetujuan orang tua, dan tanpa kelainan kongenital, riwayat infeksi berat, dan trauma kepala. Sampel diambil menggunakan metode konsekutif sampling dengan jumlah minimal 33 sampel. Data dianalisis dengan uji Fisher's exact.

\section{HASIL PENELITIAN}

Berdasarkan penelitian yang dilakukan didapatkan 44 sampel. Sepuluh sampel dieksklusikan karena tidak memenuhi kriteria inklusi sehingga tersisa 34 anak. 
Enam diantaranya dieksklusi karena memiliki status gizi kurang atau buruk, dua dengan epilepsi, satu dengan riwayat spasme infantil, dan satu dengan Erb's palsy. Berikut adalah hasil penelitian berdasarkan data yang diambil langsung melalui kuesioner dan pemeriksaan fisik.

Tabel 1. Distribusi jenis kelamin

\begin{tabular}{lcc}
\hline Lingkar Kepala & $\mathrm{n}$ & $\%$ \\
\hline Laki-laki & 17 & 50 \\
Perempuan & 17 & 50 \\
TOTAL & 34 & 100 \\
\hline
\end{tabular}

Tabel 2. Distribusi umur

\begin{tabular}{|c|c|c|c|}
\hline Umur & & $\mathrm{n}$ & $\%$ \\
\hline 3 bulan & & 6 & 17,7 \\
\hline 4 bulan & & 6 & 17,7 \\
\hline 5 bulan & & 3 & 8,8 \\
\hline 6 bulan & & 6 & 17,7 \\
\hline 7 bulan & & 1 & 2,9 \\
\hline 8 bulan & & 1 & 2,9 \\
\hline 9 bulan & & 4 & 11,8 \\
\hline 10 bulan & & 3 & 8,8 \\
\hline 11 bulan & & 3 & 8,8 \\
\hline \multirow[t]{2}{*}{12 bulan } & & 1 & 2,9 \\
\hline & TOTAL & 34 & 100 \\
\hline
\end{tabular}

Tabel 3. Distribusi frekuensi sampel berdasarkan lingkar kepala

\begin{tabular}{lcc}
\hline Lingkar Kepala & $\mathrm{n}$ & $\%$ \\
\hline Normal & 33 & 97,1 \\
Mikrosefalus (tidak normal) & 1 & 2,9 \\
Makrosefalus (tidak normal) & 0 & 0
\end{tabular}

$\begin{array}{lll}\text { TOTAL } & 34 & 100\end{array}$

Tabel 4. Distribusi lingkar kepala berdasarkan KPSP yang digunakan

\begin{tabular}{lccccc}
\hline \multirow{2}{*}{ KPSP } & & \multicolumn{3}{c}{ Lingkar Kepala } \\
\cline { 3 - 6 } & $\mathrm{n}$ & Normal & \multicolumn{2}{c}{ Tidak } \\
& & & & \multicolumn{2}{c}{ Normal } \\
\cline { 3 - 6 } & & $\mathrm{N}$ & $\%$ & $\mathrm{n}$ & $\%$ \\
\hline 3 bulan & 15 & 14 & 41,2 & 1 & 2,9 \\
6 bulan & 8 & 8 & 23,6 & 0 & 0 \\
9 bulan & 10 & 10 & 29,4 & 0 & 0 \\
12 bulan & 1 & 1 & 2,9 & 0 & 0 \\
TOTAL & 34 & 33 & 97,1 & 1 & 2,9 \\
\hline
\end{tabular}

Tabel 5. Distribusi frekuensi sampel berdasarkan perkembangan

\begin{tabular}{lcc}
\hline Perkembangan & $\mathrm{n}$ & $\%$ \\
\hline Normal & 30 & 88,2 \\
Tidak normal & 4 & 11,8 \\
\multicolumn{1}{c}{ TOTAL } & 34 & 100 \\
\hline
\end{tabular}

Tabel 6. Distribusi perkembangan berdasarkan KPSP yang digunakan

\begin{tabular}{lccccc}
\hline & & \multicolumn{3}{c}{ Perkembangan } \\
\cline { 3 - 6 } KPSP & $\mathrm{n}$ & Normal & \multicolumn{2}{c}{ Tidak } \\
& & & Normal \\
\cline { 3 - 6 } & & $\mathrm{n}$ & $\%$ & $\mathrm{n}$ & $\%$ \\
\hline 3 bulan & 15 & 11 & 32.3 & 4 & 11.8 \\
6 bulan & 8 & 8 & 23,6 & 0 & 0 \\
9 bulan & 10 & 10 & 29,4 & 0 & 0 \\
12 bulan & 1 & 1 & 2,9 & 0 & 0 \\
TOTAL & 34 & 30 & 88,2 & 4 & 11,8 \\
\hline
\end{tabular}

Tabel 7. Hubungan lingkar kepala dan perkembangan

\begin{tabular}{lccccc}
\hline & & \multicolumn{3}{c}{ Perkembangan } \\
\cline { 3 - 6 } $\begin{array}{l}\text { Lingkar } \\
\text { kepala }\end{array}$ & $\mathrm{n}$ & \multicolumn{2}{c}{ Normal } & \multicolumn{2}{c}{$\begin{array}{c}\text { Tidak } \\
\text { Normal }\end{array}$} \\
\cline { 3 - 6 } & & $\mathrm{n}$ & $\%$ & $\mathrm{n}$ & $\%$ \\
\hline Normal & 33 & 29 & 85,3 & 4 & 11,8 \\
$\begin{array}{l}\text { Tidak } \\
\text { normal }\end{array}$ & 1 & 1 & 2,9 & 0 & 0 \\
$\quad$ TOTAL & 34 & 30 & 88,2 & 4 & 11,8 \\
\hline & & & & \multicolumn{3}{c}{$\mathrm{p}=0,882$} \\
\hline
\end{tabular}

\section{PEMBAHASAN}

Penelitian ini dilakukan pada anakanak berusia 3-12 bulan yang datang untuk imunisasi di Poli Bayi \& Tumbuh Kembang RSUP Prof. Dr. R. D. Kandou Manado. Sampel minimal yang diperlukan adalah sebanyak 33 sampel. Dari penelitian yang dilakukan sejak bulan November 2015 hingga Januari 2016 didapatkan sampel yang memenuhi kriteria inklusi sebanyak 34 anak.

Sampel terdiri dari 17 anak laki-laki dan 17 anak perempuan terlihat pada tabel 1 dengan usia rata-rata 6,4 bulan terlihat 
pada tabel 2. Pada tabel 3 dapat dilihat bahwa terdapat 33 anak dengan lingkar kepala normal dan satu anak dengan lingkar kepala tidak normal. Tabel 5 menunjukkan empat anak dengan perkembangan tidak normal. Semua anak yang memiliki lingkar kepala atau perkembangan tidak normal adalah anakanak yang diperiksa menggunakan KPSP 3 bulan.

Berdasarkan lingkar kepalanya, pada tabel 7 dapat dilihat bahwa 29 anak dengan lingkar kepala normal memiliki perkembangan yang normal. Empat anak dengan lingkar kepala normal memiliki perkembangan yang tidak normal. Satu anak memiliki lingkar kepala tidak normal dengan perkembangan yang normal.

\section{Dari hasil uji Fisher's exact,} didapatkan nilai $\mathrm{p}>0,05$ yang menunjukkan bahwa secara statistik tidak ada hubungan yang bermakna antara lingkar kepala dan perkembangan bayi di Poli Bayi \& Tumbuh Kembang RSUP Prof. Dr. R. D. Kandou Manado. Hasil ini berbeda dengan hasil penelitian yang dilakukan oleh Uswatun \& Wulandari ${ }^{25}$ yang dilakukan di Jawa Tengah di mana didapatkan hubungan yang secara statistik signifikan antara lingkar kepala dan perkembangan bayi.

Perbedaan yang terjadi mungkin disebabkan karena perbedaan metodologi penelitian. Pada penelitian tersebut digunakan distribusi sampel yang lebih luas, jumlah sampel yang lebih banyak, kriteria inklusi dan eksklusi yang lebih sedikit serta pemantauan perkembangan menggunakan DDST-II yang lebih sensitif dan spesifik daripada KPSP. ${ }^{25}$

Keterbatasan dari penelitian ini juga turut memengaruhi hasil yang didapatkan. Salah satu keterbatasan yang terdapat dalam penelitian ini ialah penilaian yang dilakukan terhadap sampel hanya dilakukan satu kali karena menggunakan desain penelitian potong lintang.

\section{KESIMPULAN}

Dari penelitian dapat diambil kesimpulan bahwa tidak terdapat hubungan yang bermakna antara lingkar kepala dan perkembangan pada bayi usia tiga sampai 12 bulan di Poli Bayi \& Tumbuh Kembang RSUP Prof. Dr. R.D. Kandou Manado. Sebagian besar bayi memiliki ukuran lingkar kepala dan perkembangan yang normal.

\section{Saran}

1. Untuk penelitian lebih lanjut dianjurkan menggunakan jumlah sampel yang lebih banyak, distribusi yang lebih luas, dan penilaian perkembangan yang lebih sensitif dan spesifik menggunakan DDST-II.

2. Bayi dengan perkembangan yang tidak normal harus segera dilakukan intervensi.

3. Pengukuran lingkar kepala dan KPSP dianjurkan sebagai pemeriksaan rutin pada bayi.

\section{DAFTAR PUSTAKA}

1. The Royal Children's Hospital Melbourne. Developmental delay: an information guide for parents. Melbourne: The Royal Children's Hospital; 2009.

2. Soetjiningsih. Perkembangan anak dan permasalahannya. Dalam: Narendra M, Sularyo S, Soetjiningsih, Suyitno $\mathrm{H}$, Ranuh IGN, penyunting. Buku ajar I tumbuh kembang anak dan remaja. Jakarta: Sagung Seto; 2002. h. 86-94

3. Suwarba IGN, Widodo DP, Handryastuti RAS. Profil klinis dan etiologi pasien keterlambatan perkembangan global di Rumah Sakit Cipto Mangunkusumo Jakarta. Sari Pediatri. 2008; 10:255-61.

4. Shevell M, Ashwal M, Donley D, Flint J, Gingold M, Hirtz D, Majnemer A, dkk. Practice parameter: Evaluation of the child with global development delay. Neurology. 2003; 60:367-80. 
5. Cleary MA, Green A. Development delay: when to suspect and how to investigate for an inborn error of metabolism. Arch Dis Child. 2005; 90:1128-32

6. Simeonsson RJ, Sharp MC. Developmental delays. Dalam: Hoekelman RA, Friedman SB, Nelson NM, Seidel HM, penyunting. Primary Pediatric Care; edisi-2. St Louis, MO: Mosby-Year Book; 1992: 867-70.

7. Sussanti A, Fadlyana E, Nataprawira HM. Manfaat intervensi dini anak usia 6-12 bulan dengan kecurigaan penyimpangan perkembangan. MKB. 2014; 46:63-7.

8. Fadlyana E, Alishjahbana A, Nelwan I, Noor M, Selly, Sofiatin Y. Pola keterlambatan perkembangan balita di daerah pedesaan dan perkotaan Bandung, serta faktor-faktor yang mempengaruhinya. Sari Pediatri. 2003; 4:168-75.

9. Drotar D, Stancin T, Dworkin H, Sices L, Wood S. Selecting developmental surveillance and screening tools. Pediatric in Review. 2008; 29:e52-8.

10. Sand N, Silverstein M, Glascoe FP, Gupta VB, Tonniges TP, O'Connor KG. Pediatricians' reported practices regarding developmental screening: do guidelines work? do they help? Pediatrics. 2005; 116:174-9.

11. Sices L, Feudtner C, McLaughlin J, Drotar D, Williams M. How do primary care physicians identify young children with developmental delays? A national survey. J Dev Behav Pediatr. 2003; 24:409-17.

12. Glascoe FH. Early detection of developmental and behavioral problems. Pediatrics in Review. 2000; 21:272-80.

13. Soetjatmiko. Deteksi dini gangguan tumbuh kembang balita. Sari Pediatri. 2001; 3:175-88.

14. Passat J. Kelainan perkembangan. Dalam: Soetomenggolo TS, Ismael S, penyunting. Buku ajar neurologi anak. Jakarta: BP IDAI; 1999. h. 104-136
15. Soetomenggolo TS. Pemeriksaan neurologis pada anak dan anak. Dalam: Soetomenggolo TS, Ismael $\mathrm{S}$, penyunting. Buku ajar neurologi anak. Jakarta: BP IDAI; 1999. h. 1-35.

16. Narendra MB. Penilaian pertumbuhan dan perkembangan anak. Dalam: Narendra M, Sularyo S, Soetjiningsih, Suyitno H, Ranuh IGN, penyunting. Buku ajar I tumbuh kembang anak dan remaja. Jakarta: Sagung Seto; 2002. h. 95-111.

17. Coronado R, Giraldo J, Macaya A, Roig M. Head circumference growth function as a marker of neurological impairment in cohort of microcephalic infants and children. Neuropediatrics. 2012; 43:271-4.

18. Pettit RE, Kilroy AW, Allen JH. Macrocephaly with head growth parallel to normal growth pattern: neurological, developmental, and computerized tomography findings in full term infants. Arch Neurol. 1980; 37:518-21.

19. Przytycki A, Burgin R. Microcephalic children without mental retardation. Harefuah. 1992; 122:566-8.

20. Frakenburg WK, Dodds J, Archer P, Shapiro H, Bresnick B. The Denver II: A major revision and restandardization of the Denver Developmental Screening Test. Pediatrics. 1992; 89:91-7.

21. Kadi FA, Garna H, Fadlyana E. Kesetaraan hasil skrining risiko penyimpangan perkembangan menurut cara kuesioner praskrining perkembangan (KPSP) dan Denver II pada anak usia 12-14 tahun dengan berat lahir rendah. Sari Pediatri. 2008; 10:29-33.

22. Dhamayanti M. Kuesioner praskrining perkembangan (KPSP) anak. Sari Pediatri. 2006; 8:9-15.

23. Departemen Kesehatan Republik Indonesia. Kuesioner praskrining perkembangan. Dalam: Rusmil K, Hernawati I, Fadlyana E, Dhamayanti M, Dashriati, Herniyati S, et al, 
penyunting. Pedoman pelaksanaan stimulasi, deteksi dini dan intervensi dini tumbuh kembang anak di tingkat pelayanan kesehatan dasar. Jakarta: Depkes RI; 2005. h.71-86.

24. Sonnander K. Early identification of children with developmental disabilities. Acta Paediatrica. 2000; 89 Suppl 434:17-23

25. Uswatun A, Wulandari A. Hubungan lingkar kepala dengan perkembangan anak usia 12-24 bulan di posyandu tgolowatu Kemalang Klaten. Jurnal Involusi Kebidanan. 2011; 1:3 